\title{
A Practical Swelling Constitutive Model of Anhydrite and its Application on Tunnel Engineering
}

\section{Zhenkun Hou ( $\nabla$ zhenkunhoucqu@163.com )}

Guangdong University of Technology

Jianxun Wu

Guangdong University of Technology

\section{Research Article}

Keywords: anhydrite, tunnel engineering, swelling, constitutive model

Posted Date: January 17th, 2022

DOI: https://doi.org/10.21203/rs.3.rs-1224616/v1

License: (c) (1) This work is licensed under a Creative Commons Attribution 4.0 International License. Read Full License 


\title{
A practical swelling constitutive model of anhydrite and its application on tunnel engineering
}

\author{
Jianxun Wu ${ }^{\text {a,b }}$, Zhenkun Hou ${ }^{a, c^{*}}$
}

a. School of Civil and Transportation Engineering, Guangdong University of Technology, Guangzhou 510006, Guangdong, China;

b. East China Electric Power Design Institute, Shanghai 200002, China;

c. State Key Laboratory of Geomechanics and Geotechnical Engineering, Institute of Rock and Soil Mechanics, Chinese Academy of Sciences, Wuhan, Hubei 430071, China.

\begin{abstract}
Swelling of anhydrite rock is a major threat in tunneling engineering, causing serious damage to tunnels as well as producing high additional costs during tunnel construction and operation. Reliable prediction of swelling pressures and deformations based on conventional swelling constitutive models is extremely difficult. This paper focuses on developing a practical swelling constitutive model of anhydrite for tunnel engineering. Firstly, swelling tests of natural anhydrite samples, focusing on time effect, were designed and conducted. The test results show swelling strain-time can be better described by S-curve model, and swelling stress-strain can be better described by quadratic model. Secondly, a swelling constitutive model with consideration of time effect was developed to reproduce the swelling behavior of anhydrite observed in swelling tests. This model can track the evolution of swelling activity in the tunnelling, which has practical significance for process simulation and process control of swelling disaster. Then this model was implemented within ANSYS for numerical simulation of Lirang tunnel. Based on simulation results, some useful measures were proposed and applied to this tunnel, and got a satisfactory result according to the on-site feedback information.
\end{abstract}

Keywords anhydrite; tunnel engineering; swelling; constitutive model;

* Corresponding author: Zhenkun Hou, E-mail address: 979357924@qq.com(Z. Hou) 


\section{Introduction}

Anhydrite rock is widely distributed in the world, and its negative impacts on tunnel engineering are reported increasingly [1,2], especially in China due to the high-speed development of transportation industry [3]. The main composition of anhydrite that $\mathrm{CaSO} 4$ will transform into $\mathrm{CaSO} 4 \cdot 2 \mathrm{H} 2 \mathrm{O}$ after meeting water, which results in an increase of the solid volume by some $61 \%$. Correspondingly major swelling deformations can result. If tunnel is constructed through anhydrite stratum, swelling will cause engineering disasters, such as flfloor heave, beyond limit or destruction of lining, and collapse of surrounding rock [1,4]. So the swelling of anhydrite rock is a major threat in tunnel engineering, causing serious damage to tunnels and producing high additional costs during tunnel construction and operation.

Research on this engineering problem was triggered in the early 1970's. Luo Jian et al. [5] carried out research on swelling deformation of anhydrite rock samples, and accumulated some valuable test data. F.Rauh [6,7] conducted some research related to micromechanism of anhydrite swelling, while Sch"adlich [8] paid attention to macroscopic swelling constitutive model. Microscopic swelling models based on mineral transformations in the anhydrite-gypsum-water system were studied by Anagnostou [9], Ramon [10] and Oldecop [11]. Alonso [12] and Berdugo [13] also carried out many on-site research works including monitoring and analysis of inverted arch of tunnel. A great amount of practical experience and experiment research has been gained in the last decades, but tunnelling in anhydrite is still a very challenging task, as a recent example Li Rang Tunnel in China. Reliable prediction of swelling pressures and deformations based on conventional swelling constitutive models is extremely diffiffifficult due to the following reasons:

(a) Anhydrite swelling can last a very long time. In order to minimize the test time, usually powder samples instead of rock samples were employed to carry out test for establishing model $[6,14$, 15]. For example, Liu et al. [14] used disk-shaped samples remodeled by anhydrite powder in swelling test, obtaining the relationship between the swelling stress and moisture. Actually the structure of powder sample is diffferent from that of natural rock, so the models based on test results of powder samples cannot accurately reflflect swelling behavior. 
(b) Most constitutive models for swelling rock employ Grob's swelling law [16]. These models were established based on an underlying assumption that the relationship between swelling stress and swelling strain is stable and unchangeable in the whole swelling process. In addition, the swelling stress-strain relationship described by these models usually is under the condition of complete swelling. So these models are only able to predict a fifinal swelling behavior of surrounding rock, but unable to track the evolution of swelling activity in the tunneling. However, due to the slow evolution of swelling deformations in anhydrite, the dynamic changing of swelling stress-strain before complete swelling cannot be neglected.

(c) Conventional swelling constitution models for swelling rock usually employed the logarithmic function to fifit test data of swelling stress-strain. In the interval that swelling stress is large, the function fifits the data well, whereas in the interval that swelling stress is small, the function fifits the data poorly [17]. As the above reasons, a practical swelling constitutive model of anhydrite, considering the dynamic changing of swelling stress-strain, is the key to solve tunnel engineering problems associated with anhydrite swelling. So the main objective of this paper is to develop such a model. For reason (a), we employed natural anhydrite rock samples, which were obtained by dry coring from the Lirang tunnel, to carry out experiment study aiming to get closer to on-site swelling performance. For reason (b), we introduced time efffect into swelling constitutive model, i.e. the relationship between swelling stress and strain is not stable, but changes over time. So the time factor was taken into consideration in test method with the aim of obtaining swelling stress-strain curves at difffferent point in time. For reason (c), we employed a new function instead of traditional loga rithmic function to fifit swelling stress-strain data. The detailed swelling test process and model established are presented in Section 2 and Section 3, respectively. An application case of our model is presented brieflfly in Section 4. In Section 5, we carry out a future discussion for improving this model.

\section{Swelling test}

\subsection{Sample preparation}


For swelling tests, anhydrite rocks, which occur in Lower Triassic Jialing River Group, were obtained from Lirang tunnel located in Liangping county, Chongqing, China. Firstly, X-ray difffraction qualitative analysis was used to determine the mineral composition of the anhydrite samples. The composition of these samples is $\mathrm{CaSO} 4, \mathrm{CaSO} 4 \cdot 2 \mathrm{H} 2 \mathrm{O}, \mathrm{SiO} 2, \mathrm{~F}$ e2O3, and $\mathrm{CaCO} 3$. One of analysis result is presented in Fig.1(a). Then, based on the results of qualitative analysis, a quantitative analysis was carried out to determine the content of CaSO 4 , and $\mathrm{CaSO} 4 \cdot 2 \mathrm{H} 2 \mathrm{O}$ (Table1) by employing Internal Standard Method. As shown in the Table 1, the CaSO4 content ranges from $88 \%$ to $95 \%$, and the $\mathrm{CaSO} 4 \cdot 2 \mathrm{H} 2 \mathrm{O}$ content ranges from $2 \%$ to $8 \%$, while the content of other composition(including $\mathrm{SiO} 2, \mathrm{~F}$ e2O3 andCaCO3) ranges from $2 \%$ to $5 \%$.

After mineral composition analysis, these anhydrite rocks were processed into disk-shaped samples with $61 \mathrm{~mm}$ in height and $20 \mathrm{~mm}$ in diameter according to the recommendations of ISRM (1989) [18]. The process was done air flflushed in order to avoid an early activation of the swelling process. One of these processed samples is shown in Fig.1(b).

\subsection{Swelling test apparatus}

The Single Lever Trigeminy High Pressure Oedometer Apparatus, which has a maximum capacity of $4000 \mathrm{kPa}$ for the vertical load, was employed for the swelling test. Besides, TWJ Data Auto Sampling System, which can distinguish a minimum vertical deformation of $0.001 \mathrm{~mm}$, was also employed to assist the swelling test. This system consists of computer, sensor, servo and circuit, and can be linked with the oedometer apparatuses, so it is able to automatically record the data in time. The oedometer apparatus with this system is shown in the Fig.2.

\subsection{Test method}

Swelling of anhydrite is a complicated process, which is inflfluenced by a lot of factors. This paper focus on the time factor, which aims to establish a practical model. As swelling stress-strain relationship is a reflflection of swelling potential of rock materials, it is changing over contact time with water. It is possible to obtain a complete swelling stress-strain curve at one point in time with the method suggested by ISRM [18]. However, it is not possible to obtain a series of complete swelling stress-strain curves of a separate sample at various points in time during the swelling process, because 
a separate sample is unable to be reused. For this problem, we employed the swelling stress-strain curves of several samples after diffferent contact time with water instead of the swelling stress-strain curves of a separate anhydrite sample at various point in time, i.e. disregarding the inflfluence of individual difffference of samples to swelling. The specifific method is presented as follows:

(a) Free swelling test with lateral confifinement(FLC). At this stage, we aimed at establishing the relationship between swelling strain and time. Firstly, a disk-shaped anhydrite sample was embedded into a metal ring, inner wall of which was painted by vaseline. This metal ring was used to confifine the lateral of sample. Then the sample with the metal was put into the water container of the oedometer apparatus, and both the top and bottom of the sample were placed a porous plate. After the sample setup, water was poured slowly into the water container until water surface was above the sample $5 \mathrm{~mm}$. The axial deformation was recorded by the data auto sampling system after watering until reaching design time, and the water level was kept unchangeable during the test process. Nine disk-shaped anhydrite samples were tested with the above method but difffferent contact time with water. The swelling time of each sample is shown in Table 2 .

(b) Axial swelling stress and strain test with lateral confifinement(ALC). At this stage we aimed at obtaining the swelling stress-strain relationship of above nine samples which had experienced difffferent swelling time. After a sample fifinished design swelling time, the oedometer with the sample is put in loading frame, and loaded stepwise until the measured deformations due to swelling were compensated [18], i.e. swelling deformations were compressed back to nearly zero. The compression deformation under each load was recorded, so that swelling stress-strain curve of each sample was obtained.

\subsection{Test results}

Fig. 3 is the relationship between swelling strain and time from FLC. The swelling strain of all samples increases over the time, even the swelling strain of NO.9, which has a longest swelling time 119 days, still not fifinished and could continue in a constant rate. One conclusion from this fifigure is that the growth rate of swelling strain of anhydrite increases initially, in a positive acceleration phase, then declines in a negative acceleration phase until at a relatively stable positive value, i.e. the slope 
of swelling strain-time curve increases initially then decreases to a relatively stable state. The swelling process of anhydrite is a complicated physico-chemical reaction, before the water completely inflflowed into anhydrite rock, the swelling is able to be controlled by both osmotic effffect of water, which is related to the speed of water inflflow into the rock, and sulfate hydration(chemical reaction of $\mathrm{CaSO} 4+2 \mathrm{H} 2 \mathrm{O}=\mathrm{CaSO} 4 \cdot 2 \mathrm{H} 2 \mathrm{O}$ ), so the growth rate of swelling strain is changing [20] [21]. After the rock completely contact water, the dominate reason is the sulfate hydration, of which the reaction rate is relatively stable and is able to continue, so the swelling strain can sustain increasing with a relatively stable rate, this is also the reason why the latter part of each swelling strain-time curve is approximately an oblique line.

Fig. 4 is the relationship between swelling stress and stain from ALC. Swelling stress is defifined as the ratio of the force which can inhibit the swelling strain caused by the water seeped into the sample to the sectional area of the sample [22]. With the increase in swelling stress, the swelling strain decreases shown in Fig.4, and all stress-strain curves behave as concave characteristic. The intersection of each curve with swelling strain axis, which is the swelling strain of correspondingsample at the end of FLC, goes up with the sample numbers increase. It indicates that usually the longer swelling time, the larger swelling strain. By extending the bottom of each curve, the intersection of each curve with swelling stress axis can be obtained, which also shows an increasing trend with the sample numbers increase. It indicates that the swelling stress under the condition of completely inhibiting swelling strain goes up with increasing swelling time.

\section{Model established}

\subsection{Swelling strain-time model}

Xiaoli Liu et al. ever employed the exponential model(shown in Fig.5) to describe the swelling strain-time of pure clay rock as follows [23]:

$$
\varepsilon_{t}=\varepsilon_{\infty}\left(1-e^{-k t}\right)
$$

where, $\mathrm{t}$ is time, $\varepsilon \mathrm{t}$ is swelling strain at time $\mathrm{t}, \varepsilon_{\infty}$ is fifinal swelling strain, $\mathrm{k}$ is coeffiffifficient depending on characteristic of rock. This model is able to describe the swelling stress-time of pure clay rock well, but not for anhydrite rock. Firstly, it cannot describe the changing process of growth 
rate of swelling strain, which is controlled by the coupled effffect of both osmotic effffect and hydration efffect, before the water in full contacts with rock. Although such a changing process lasts a short time in laboratory test, it can last a long time in fifiled test(Several on-suit tests show a similar changing process of growth rate of swelling deformation, and the duration can up to several months [2]), i.e. the changing process will be more obvious with increasing the size of rock sample. Such a long duration of changing process has impact on tunnel construction and design. Secondly, this model cannot describe well the relatively stable status of growth rate of swelling strain after water in full contacts rock, which is very important for predicting the fifinal swelling deformation in tunnel engineering.

For the above problem, we employed a S-curve model, which has been widely used to show the growth rate of a variable changed over time [24], to describe the swelling strain-time due to the fact that curve of each sample in Fig.3 is approximately S-shaped. The model is shown in Fig.5 as follows:

$$
\varepsilon_{t}=\left(\frac{\varepsilon_{\infty}}{1+a t^{-b}}\right)
$$

where, $\mathrm{a}$ and $\mathrm{b}$ are coeffiffifficients related to characteristic of rock. In this equation, if time tends to infifinity, the $\varepsilon t$ will tend to a maximal swelling strain $\varepsilon \infty$. It indicates that swelling strain is not able to increase to infifinity, but have an upper limit. This is agree with the practical situation, and severalpapers( [6] [25]) point out that the upper limit, i.e. maximal swelling strain $\varepsilon \infty$, of pure anhydrite is $61 \%$. Actually, $61 \%$ is an ideal value, and is never obtained in test. So in the practical application of this model, $\varepsilon \infty$, just as a coeffiffifficient, should be obtained by fifitting the test data.

For better comparison, we fifitted the nine samples data by using the two swelling strain-time models, respectively. Fig.6 is the fifitting results, it is obvious that S-curve model is better than exponential model for anhydrite rock swelling strain-time, especially it can better describe the continuing increase process of swelling strain. Table 3 is summary fifits of swelling strain-time of nine samples for the two models. In terms of a separate sample, the R-squared of S-curve model is higher than that of exponential model, which also indicates S-curve model is better than exponential 
model. It should also be noted that a maximal swelling strain $\varepsilon \infty$ estimated by S-curve model is more than that by exponential, shown in Table 3 .

\subsection{Swelling stress-strain model}

Based on laboratory test of clay rocks, Grob [26-28]formulated a logarithmic model(Fig.7) to describe the swelling stress-strain :

$$
\varepsilon=K\left[1-\frac{\lg (\delta)}{\lg \left(\delta_{m}\right)}\right]
$$

Where $\varepsilon$ is swelling strain at a given axial stress $\sigma$ (i.e. swelling stress based on defifinition). $\mathrm{K}$ and $\lg (\sigma \mathrm{m})$ are coeffiffifficients depending on the rock features. As shown in Fig.7, the intersection of the logarithmic curve with the stress axis supplies the coeffiffifficient $\sigma \mathrm{m}$. For stresses $\sigma$ larger than $\sigma \mathrm{m}$, no more swelling strains occur. For small stresses, application scope of the swelling law is limited by minimum stress, because unrealistically high swelling strains would result otherwise. Furthermore, very small stresses lead to decomposition processes in the rock, which cannot be described by the swelling law [27].

For this problem, we employed left part of a parabola opening upwards, vertex of which is on $\mathrm{X}$-axis, to describe the swelling stress-strain due to curve feature of each sample in Fig.4. This model is a quadratic function as the following, and has intersections with both $\mathrm{X}$-axis and Y-axis, shown in Fig.7.

$$
\varepsilon=\rho\left(\delta-\delta_{m}\right)^{2}
$$

Where $\varepsilon$ is swelling strain, $\sigma$ is swelling stress. $p$ and $\sigma \mathrm{m}$ are coeffiffifficients depending on the feature of rock. In terms of a separate sample, om is swelling stress under swelling strain inhibited completely, while pom is swelling strain without inhibiting.

For comparison, we fifitted the data of swelling stress-strain by using the two models, respectively. Fig. 8 is the fifitting results, it is obvious that quadratic model is better than logarithmic model for anhydrite rock swelling stress-strain, especially in the interval that swelling stress is small. Table 4 is summary fifits of swelling stress-strain of nine samples for the two models. Most R-square 
of quadratic model is higher than that of logarithmic model, which also indicates quadratic model is better.

\subsection{Swelling constitutive model with consideration of time efffect}

Unlike pure clay swelling rocks, the swelling of anhydrite rock is highly time-dependent [27]. Pure clay rock is able to fifinish swelling in several days, while anhydrite needs a very long time. In the above test, even though up to 119 days, the swelling of anhydrite rock still not fifinished and could continue. In nature, this process can take decades. The time dependency of anhydrite swelling therefore cannot be neglected. By disregarding the inflfluence of individual diffference of sample to swelling, curve of each sample in Fig.4 can be regarded as swelling stress-strain of a separate anhydrite rock at difffferent points in time. So if making these data correspond to the time, a swelling constitutive model with consideration of time effffect can be established. This model candescribe a dynamic process that swelling stress-strain curve of an individual anhydrite changing over time.

As illustrated in Section 3.2, data in Fig.4 can be better fifitted with a series of parabolas. So the dependence of swelling stress-strain on time can be established by fifinding out the movement history of intersections of parabolas with axis.

Firstly, in terms of a separate anhydrite, the intersections of parabolas with Y-axis, $\rho \delta_{m}^{2}$ (obtained by substituting $\sigma=0$ into Equation (4)), represent strain from FLC, so their movement history can be better described by Equation(2), that is:

$$
\rho \delta_{m}^{2}=\varepsilon_{t}=\frac{\varepsilon_{\infty}}{1+a t^{-b}}
$$

Secondly, the intersections of parabolas with $\mathrm{X}$-axis, $\sigma \mathrm{m}$ (obtained by substituting $\varepsilon=0$ into Equation(4)), are swelling stress under the condition of completely inhibiting swelling strain. The relationship between $\sigma \mathrm{m}$ of parabolas(be presented in Table4) and time is shown in Fig.9. $\sigma \mathrm{m}$ increases over time, while its increase rate tends to decrease. Previous researches [29-31] also indicate that $\sigma \mathrm{m}$ of swelling rock increases quickly at early stage then tends to a constant value, and its evolution over time acts out exponential feature. So we employed the following equation to describe movement history of $\sigma \mathrm{m}($ also shown in Fig. 9 as a red line): 


$$
\delta_{m}=\delta_{\infty}\left(1-e^{-c t}\right)
$$

Where, $\sigma \mathrm{max}$ and $\mathrm{c}$ are coeffiffifficients that depend on rock feature. $\sigma \mathrm{max}$ is maximal $\sigma \mathrm{m}($ when time $t$ tends to infifinity), i.e. the swelling stress under the condition of inhibiting completely swelling strain when rock completely fifinish swelling.

After fifinding out the movement history of intersections of parabolas with both $\mathrm{X}$-axis and Y-axis, the swelling constitutive model with consideration of time effffect can be established by substituting Equation(5) and Equation(6) into Equation(4),as follows:

$$
\varepsilon=\frac{\varepsilon_{\infty}\left[\delta-\delta_{\max }\left(1-e^{-c t}\right)\right]^{2}}{\delta^{2}{ }_{\max }\left(1+a t^{-b}\right)\left(1-e^{-c t}\right)^{2}}
$$

In this model, both time $t$ and swelling stress $\sigma$ are independent variables, while $\varepsilon$ is dependent variable. This model is a surface in three-dimensional space, and is established to describe the dynamic process that swelling stress-strain relationship changing over time with disregarding the inflfluence of individual diffference. As it can be regards as swelling stress-strain of an individual anhydrite rock at difffferent points in time, all data in Fig.4 was fifitted by this model using MATLAB Sftool(Surface Fitting Toolbox). Comparisons between test data and model prediction are presented in Fig. 10 , and summary fifits are presented in Table 6.

In Fig.10 test data equably distribute around the fifitting surface. It indicates that this model fifits the test data well. In the Table 6, R-square closes to 1, while both RMSE and SSE close to 0. All of them also support the view that this model can reflflect the dynamic process of swellingstress-strain of anhydrite well. It is very meaningful that the estimated value of $\varepsilon \infty$ by this model, which is a fifinal swelling strain, close to its theory value $61 \%[1,32]$ as pure anhydrite rock. The error between estimated value and theory value may be caused by the CaSO4 content.

\section{Application of model}

This study is part of a project carried out at Liramg tunnel in Chongqing, China. The left channel from ZK14+582 to ZK14+907 and the right channel from K14+599 to K14+920 in Li Rang Tunnel go through about $300 \mathrm{~m}$ anhydrite-gypsum stratum. In this section, the swelling constitutive model(7) 
was implemented within ANSYS to simulate the inflfluence of swelling on the tunnel during the construction period, so that some practical measures based on simulation results were proposed to counteract the swelling problem.

Previous simulation for surrounding rock swelling usually used the method of simulating thermal expansion for reference. For example, Miao et al. ever simulated swelling of surrounding rock by corresponding humidity stress fifield to temperature fifield [33]. However, as our model considering the time efffect, we used the method of simulating creep for reference to simulate swelling. Our model is essentially for describing strain under the effffect of stress and time. So with user-defifined creep subroutine offffered by ANSYS, we can directly simulate swelling.

Based on geologic survey data and design documents of Lirang tunnel, A 2D fifinite element model is established using ANSYS(shown in Fig.11). plane42 element was employed to simulate the surrounding rock, link1 element was employed to simulate rock bolts, and beam3 element was employed to simulate fifirst lining. The basic material parameters for both rock stratums and support structure are given in Table 5. As the samples were obtained from Lirang tunnel, so the parameters listed in Table 6 can be employed for simulating swelling immediately. In this study, we only simulated the process from excavation to the begin of second lining(36 day in all according to the design documents). Some useful results are presented in Fig. 12 and Table 7.

Fig.12(a) and Fig.12(b) are deformations distribution of surrounding rock on day 36. Shown in Fig.12(a), the arch crowns go down $24.5 \mathrm{~cm}$, and the flfloors are uplifted up to $19.7 \mathrm{~cm}$. It indicates that not only the roof, but also the flfloor of the tunnel are subjected to larger deformation due to the efffect of swelling. Fig.12 (b) shows that the maximal deformation of surrounding rock is $27.6 \mathrm{~cm}$. Fig.12(c) and Fig.12(d) are the mechanical performance of support structures. Shown in Fig.12(c), the maximal axial force of beam elements on day 36 is $50396 \mathrm{kN}$ coming from arch springing. In the simulation results, the beam elements are mainly subjected to axial force, while both shearing force and bending moment of them are very small, so we only list the maximal values of shearing force and bending moment in Table 7 and do not present their distribution fifigures here. Based on the mechanical performance of beam elements, a maximal compression stress of fifirst liningthat $7.4 \mathrm{MPa}$ is worked out. In Fig.12(d), the maximal axial force of link elements is $197.86 \mathrm{kN}$, which also comes 
from the arch springing. Based on the axial force characteristics of link elements, the maximal tensile stress of rock bolt that 100.4 MPa was worked out, which is less than design strength $130 \mathrm{MPa}$. Based on the simulation results, we gave some useful and quantitative measures for counteracting the swelling problem, and list three predominant measures as follows:

(a) In consideration that the maximal deformation surrounding the cross-section of tunnel is 27.6 $\mathrm{cm}$, the reserved deformation with $40 \mathrm{~cm}$ in thickness was reduced to $30 \mathrm{~cm}$.

(b) Based on the simulation results that the flfloor of the tunnel get an upheaval of $19.7 \mathrm{~cm}$, an overbreak with $20 \mathrm{~cm}$ in thickness under the inverted arch was set within laying some gravel as a buffffer layer.

(c) As maximal tensile stress of rock bolt is not beyond the strength tensile, the length and ring direction installation intervals of rock bolts still followed initial design. At the same time, considering that arch springing is subjected to a lager force, we suggested increasing the quantity of rock bolts there when necessary.

The above measures have already applied to Lirang tunnel, and a satisfactory result was obtained, especially, the revise of reserved deformation provide scientifific basis for cost saving. According to the on-site feedback: the updated reserved deformation is reasonable because of no beyond limit phenomenon, the measures for inverted arch are also reasonable because of no upheaval phenomenon, and no collapse of surrounding rock and damage of support structure during construction period, so such a simulation using ANSYS is able to effffectively guide tunneling through anhydrite formation.

\section{Discussion}

The swelling constitutive model developed in this study is in principle capable of reproducing the swelling behavior of anhydrite as observed in swelling tests. As described in test method, this model was established under the situation that fifinite rock subjected to enough water. However, this is difffferent from realistic situation that water content of surrounding rock is difffferent at difffferent positions in tunnel. In other words, our model is unable to consider the water content of rock, so it is unable to reflflect diffference of swelling deformation among diffferent positions in tunnel due to 
nonuniform distribution of groundwater. For the above problem, we carry out a further discussion for improving model in this section.

Existing research supports the view that the main mechanics of anhydrite swelling is the growth of $\mathrm{CaSO} \cdot 2 \mathrm{H} 2 \mathrm{O}$ crystal, and the volume swelling strain can be expressed as follows $[11,32]$ :

$$
\frac{d \varepsilon_{v}}{d t}=\frac{\gamma}{\rho_{D H}} \frac{d m_{D H}}{d t}
$$

Where, $\varepsilon_{v \text { is volume swelling strain. }}{ }^{\gamma}$ is a coeffiffifficient which reflflects the swelling effffect causedbycrystal growth. $m_{D H}$ is the water consumed by CaSO $4 \cdot 2 \mathrm{H} 2 \mathrm{O}$ crystal growth. $\rho_{D H}$ idensity of $\mathrm{CaSO} 4 \cdot 2 \mathrm{H} 2 \mathrm{O}$ crystal(at the temperature $20{ }^{\circ} \mathrm{C}, \rho \mathrm{DH}=2320 \mathrm{~kg} / \mathrm{m} 3$ ).

Assuming $\mathrm{w}$ is the volumetric water content of anhydrite, based on its defifinition:

$$
\omega=\frac{m_{\omega}}{m_{\gamma}} \rho_{d}
$$

Where $m_{\omega}$ is the mass of water in anhydrite rock, ${ }^{m}{ }_{\gamma}$ is the drying mass of anhydrite rock, $\rho_{d}$ is rock drying density.

Taking derivative of Equaction (9) with respect to time $t$, then the following equation is obtained:

$$
\frac{d m_{\gamma}}{d t}=\frac{d \omega}{d t} \frac{m_{\gamma}}{\rho_{d}}
$$

Assuming that mass change of water in rock only caused by two reasons, one is that water is consumed by $\mathrm{CaSO} 4 \cdot 2 \mathrm{H} 2 \mathrm{O}$ crystal growth, setting as $m_{D H}$. The other one is that water losses due to the evaporation and diffffusion, setting as $m_{l}$, so the following equation can be obtained:

$$
\frac{d m_{\gamma}}{d t}=\frac{d m_{D H}}{d t}+\frac{d m_{l}}{d t}
$$

Substituting Equation (10) to Equation (11), we can obtain:

$$
\frac{d m_{D H}}{d t}=\frac{d \omega}{d t} \frac{m_{\gamma}}{\rho_{d}}-\frac{d m_{l}}{d t}
$$

Then, substituting Equation (12) to Equation (8), we can obtain: 


$$
\frac{d \varepsilon_{v}}{d t}=\frac{\gamma}{\rho_{D H}}\left(\frac{d \omega}{d t} \frac{m_{\gamma}}{\rho_{d}}-\frac{d m_{l}}{d t}\right)
$$

If we take integral of both sides of Equation (13) with respect to time, we can get a new relationship between swelling strain and time.

$$
\varepsilon_{v}=\int_{0}^{t} \frac{\gamma}{\rho_{D H}}\left(\frac{d \omega}{d t} \frac{m_{\gamma}}{\rho_{d}}-\frac{d m_{l}}{d t}\right) d t=\frac{\gamma}{\rho_{D H}}\left(W(t) \frac{m_{\gamma}}{\rho_{d}}-L(t)\right)
$$

Where $\mathrm{W}(\mathrm{t})$ is a function employed to describe volumetric water content changing over time during swelling process. $\mathrm{L}(\mathrm{t})$ is a function employed to describe evaporation and diffffusion of water. The Equation (14), deduction of which is based on the microcosmic swelling mechanics, considers the mass change of water in rock. However, in this equation, the items $W(t)$ and $L(t)$ are unknown, so we will carry out research on obtaining specifific expressions of the two items by using test method in the follow-up work. After this, a complete expression of $\varepsilon_{v}$ can be obtained. By employing $\varepsilon_{v}$ instead of $\varepsilon_{t}$ in Equation (5), a new expression of q is obtained, so that a new swelling constitutive model with consideration of both mass change of water in rock and time is established, and such a model is able to simulate the swelling changing over time at diffferent positions in tunnel.

\section{Conclusion}

Swelling tests of natural anhydrite samples were designed and conducted in this study. In the test results, the data of swelling strain-time of anhydrite can be better fitted by S-curve model than by exponential model. The data of swelling stress-strain can be better fitted by quadratic model than by logarithmic model, especially in the interval that stress is small.

A swelling constitutive model with consideration of time effect was developed to reproduce the swelling behavior of anhydrite observed in swelling tests. This model is able to describe the dynamic changing of swelling stress-strain of anhydrite in the whole swelling process, so this model can match the construction process of tunnel with the swelling evolution of surrounding rock, which has practical significance for process simulation and process control of tunnel engineering disaster caused by anhydrite swelling. In addition, as introducing time effect into swelling constitutive model, the simulation of swelling can be easier achieved by using the simulation of creep for reference. 
The swelling constitutive model was implemented within ANSYS for numerical simulation of Lirang tunnel. This simulation result shows that both the roof and floor of tunnel are subjected to a larger deformation due to swelling, and the arch springing should be paid enough attention. Based on simulation results, some useful measures were proposed and applied to Lirang tunnel, and got a satisfactory result according to the feedback information from on-site.

Model developed in this paper is enough practical for solving engineering problem. However, the impossibility of reproducing the swelling deformation difference among different positions in tunnel reveals that our understanding of swelling influenced by water content is still incomplete, hence, there is an open field of research in the relationship between water content and swelling of anhydrite.

\section{References}

[1] Butscher C, Mutschler T, Blum P. Swelling of Clay-Sulfate Rocks: A Review of Processes and Controls[J]. Rock Mechanics and Rock Engineering, 1-17.

[2] Alonso E E, Berdugo I R, Ramon A. Extreme expansive phenomena in anhydritic-gypsiferous claystone: the case of Lilla tunnel[J]. Gotechnique, 2013, 63(7): 584-612.

[3] Wu Yinliang. The engineering geological characteristic gypsum rock and the damage mecha nism on tunnel concrete structure[D]. Wuhan. China University of Geosciences,2013.

[4] Anagnostou G. Untersuchungen zur Statik des Tunnelbaus in quellf?higem Gebirge[M]. vdf Hochschulverlag AG, 1992.

[5] Luo JianGypsumbearing rock group and its effffect on tunnel engineering[J]Journal of Southwest Jiaotong University1978(1)63-72.

[6] Rauh F, Spaun G, Thuro K. Assessment of the swelling potential of anhydrite in tunnelling projects[C]//Pre-Congress Proceedings 10th IAEG Congress, paper. 2006 (473).

[7] Rauh F, Thuro K. Investigations on the swelling behavior of pure anhydrites[C]//1st Canada US Rock Mechanics Symposium. American Rock Mechanics Association, 2007.

[8] Sch“adlich B, Marcher T, Schweiger H F. Application of a constitutive model for swelling rock to tunnelling[J]. Geotech Eng, 2013, 44: 47-54. 
[9] Anagnostou G, Pimentel E, Serafeimidis K. Swelling of sulphatic claystonesCsome fundamen tal questions and their practical relevance/. Quellen von sulfatfhrenden TonsteinenCThemen der Grundlagenforschung und ihre praktische Bedeutung[J]. Geomechanics and Tunnelling, 2010, 3(5): 567-572.

[10] Ramon Tarragona A. Expansion mechanisms in sulphated rocks and soils[J]. 2014.

[11] Oldecop L, Alonso E. Modelling the degradation and swelling of clayey rocks bearing calcium sulphate[J]. International Journal of Rock Mechanics and Mining Sciences, 2012, 54: 90-102. [12] Alonso E, Gens A, Berdugo I, et al. Expansive behaviour of a sulphated clay in a railway tunnel[C]//PROCEEDINGS OF THE INTERNATIONAL CONFERENCE ON SOIL ME CHANICS AND GEOTECHNICAL ENGINEERING. AA BALKEMA PUBLISHERS, 2005, 16(3): 1583.

[13] Berdugo I R. Tunnelling in sulphate-bearing rocksCexpansive phenomena[J]. Barcelona: De partment of Geotechnical Engineering and Geosciences, 2007.

[14] Liu Yanmin, Yu Hongming, et al. Research on mechanism of damage of anhydrock in dolomite layer to tunnel structure[J].Rock and Soil Mechanics, 2010, 32(9): 1000C7598.(in Chinese)

[15] Fecker I E. Inflfluence of swelling rock on tunnelling[J]. Bulletin of the International Association of Engineering Geology-Bulletin de l'Association Internationale de Gologie de l'Ingnieur, 1981, 24(1): 27-32.

[16] Serafeimidis K, Anagnostou G. On the time-development of sulphate hydration in anhydritic swelling rocks[J]. Rock mechanics and rock engineering, 2013, 46(3): 619-634.

[17] ZHAO F, ZHANG L, ZHANG M, et al. Experimental Study on Strength Characteristics of Expansive Rock along Kunming-Nanning Railway[J]. Subgrade Engineering, 2012, 2: 021.

[18] ISRM. Suggested methods for laboratory testing of argillaceous swelling rocks. Int. Journal of Rock Mechanics and Mining Sciences and Geomech. Abstr. Vol. 26, 1989, p. 415-426.

[19] Rauh F, Thuro K. Why do pure anhydrites difffer in their swelling capacity?[M]. na, 2006.

[20] Madsen FT, Muller-Vonmoos M (1989) The swelling behaviour of clays. Appl Clay Sci 4(2):143-156

[21] Kie, T. T. (1983, January 1). Swelling Rocks And The Stability Of Tunnels. International 
Society for Rock Mechanics

[22] Pimentel E. Existing Methods for Swelling Tests-A Critical Review[J]. Energy Procedia, 2015, 76: $96-105$.

[23] Liu Xiaoli, WANG Sijing, WANG Enzhi, et al. Study on time-dependent swelling constitutive relation of swelling rock[J]. Journal of Hydraulic Engineering200637(2)195-199.(in Chinese)

[24] Becker R H, Speltz L M. Putting the S-curve concept to work[J]. Research Management, 1983, 26(5): 31-33.

[25] Wittke M. Design, construction, supervision and long-term behaviour of tunnels in swelling rocks[C]/Proc Eurock. 2006: 211-216.

[26] Einstein H H, Bischoffff N. Design of tunnels in swelling rock[C]//The 16th US Symposium on Rock Mechanics (USRMS). American Rock Mechanics Association, 1975.

[27] Wittke-Gattermann P. Dimensioning of Tunnels in Swelling Rock[C]//10th ISRM Congress. International Society for Rock Mechanics, 2003.

[28] Grob, H. 1972. Schwelldruck am Beispiel des Belchentunnels, Sitzungsberichte Int. Symposium fr Untertagebau, Luzern, Switzerland, pp 99-119.

[29] Pejon O J, Zuquette L V. Effffects of strain on the swelling pressure of mudrocks[J]. International journal of rock mechanics and mining sciences, 2006, 43(5): 817-825.

[30] Kovari K, Madsen F T, Amstad C. Tunnelling with yielding support in swelling rock s[C]//ISRM International Symposium. International Society for Rock Mechanics, 1981

[31] Xie Yun, Chen Zheng-han, Sun Shu-guo, et al. Test research on three-dimensional swelling pressure of remolded expansive clay [J]. Rock and Soil Mechanics, 2007, 28(8): 1636-1642.

[32] Jeschke A A, Vosbeck K, Dreybrodt W. Surface controlled dissolution rates of gypsum in aqueous solutions exhibit nonlinear dissolution kinetics[J]. Geochimica et Cosmochimica Acta, 2001, 65(1): 27-34.

[33] Miao XiexingLarge deformation analysis of surrounding rock of a tunnel in swelling rock mass based on the humidity stress fifield theoryJJournal of China University of Mining Technolo gy199524( 1): 58-63. 
Table 1: The mineral composition of the anhydrite rock

\begin{tabular}{cccc}
\hline Sample & $\mathrm{CaSO}_{4}$ & $\mathrm{CaSO}_{4} \cdot 2 \mathrm{H}_{2} \mathrm{O}$ & Other compositions \\
\hline 1 & $90 \%$ & $8 \%$ & $2 \%$ \\
2 & $91 \%$ & $4 \%$ & $5 \%$ \\
3 & $88 \%$ & $7 \%$ & $5 \%$ \\
4 & $95 \%$ & $2 \%$ & $3 \%$ \\
\hline
\end{tabular}

Table 2: The swelling time of each sample

\begin{tabular}{cccccccccc}
\hline NO. & 1 & 2 & 3 & 4 & 5 & 6 & 7 & 8 & 9 \\
\hline Swelling time (days) & 7 & 14 & 21 & 35 & 49 & 63 & 77 & 98 & 119 \\
\hline
\end{tabular}

Table 3: Summary fits of swelling strain-time of nine samples for the exponential model and the S-curve model.

\begin{tabular}{cccc|cccc}
\hline & \multicolumn{2}{c|}{ Exponential model: $\varepsilon_{t}=\varepsilon_{\infty}\left(1-e^{-k t}\right)$} & \multicolumn{4}{c}{ S-curve model: $\varepsilon_{t}=\varepsilon_{\infty} /\left(1+a t^{-b}\right)$} \\
\cline { 2 - 8 } NO. & $\varepsilon_{\infty}$ & $k$ & R-square & $a$ & $b$ & $\varepsilon_{\infty}$ & R-square \\
\hline 1 & 0.0055 & 19.000 & 0.9082 & 0.3777 & 0.5599 & 0.0079 & 0.9727 \\
2 & 0.0081 & 1.6400 & 0.8760 & 1.1290 & 0.4658 & 0.0121 & 0.9839 \\
3 & 0.0122 & 0.5943 & 0.9299 & 54.370 & 0.4014 & 0.2516 & 0.8806 \\
4 & 0.0093 & 1.0900 & 0.9119 & 1.0990 & 0.7054 & 0.0115 & 0.9610 \\
5 & 0.0131 & 0.7403 & 0.8310 & 67.230 & 0.2789 & 0.3987 & 0.9788 \\
6 & 0.0148 & 0.3044 & 0.9412 & 3.2180 & 0.5935 & 0.0215 & 0.9923 \\
7 & 0.0157 & 0.3184 & 0.9097 & 138.60 & 0.3203 & 0.7320 & 0.9653 \\
8 & 0.0253 & 0.0214 & 0.9094 & 196.30 & 0.4645 & 0.5360 & 0.9533 \\
9 & 0.0239 & 0.0211 & 0.9322 & 194.40 & 0.4791 & 0.4666 & 0.9708 \\
\hline
\end{tabular}

Note:R-square is a number that indicates how well data fit a statistical model, and is known as the coefficient of determination. In general, the higher the R-square, the better the model fits data. The above results were obtained using Matlab Curve Fit Tool. 
Table 4: Summary fits of swelling stress-strain of nine samples for the logarithmic model and the quadratic model.

\begin{tabular}{cccc|ccc}
\hline & \multicolumn{3}{c|}{ Logarithmic model: $\varepsilon=K\left[1-l g(\sigma) / l g\left(\sigma_{m}\right)\right]$} & \multicolumn{3}{c}{ Quadratic model: $\varepsilon=p\left(\sigma-\sigma_{m}\right)^{2}$} \\
\cline { 2 - 7 } NO. & $\sigma_{m}$ & $K$ & R-square & $p$ & $\sigma_{m}$ & R-square \\
\hline 1 & 329.60 & 0.0107 & 0.8989 & $3.077 E-7$ & 151.00 & 0.8822 \\
2 & 381.30 & 0.0177 & 0.9538 & $6.915 E-8$ & 365.00 & 0.9940 \\
3 & 650.00 & 0.0188 & 0.9327 & $4.587 E-8$ & 487.30 & 0.9841 \\
4 & 830.00 & 0.0311 & 0.9490 & $3.243 E-8$ & 600.00 & 0.9937 \\
5 & 668.00 & 0.7403 & 0.8796 & $4.255 E-8$ & 632.90 & 0.9919 \\
6 & 759.80 & 0.0362 & 0.8692 & $3.004 E-8$ & 758.30 & 0.9988 \\
7 & 1020.0 & 0.0357 & 0.8761 & $1.792 E-8$ & 1050.0 & 0.9840 \\
8 & 1171.0 & 0.0352 & 0.8826 & $2.100 E-8$ & 985.30 & 0.9904 \\
9 & 1233.0 & 0.0407 & 0.9815 & $1.169 E-8$ & 1315.0 & 0.9599 \\
\hline
\end{tabular}

Table 5: The basic material parameters for both rock stratums and support structure employed for simulation analysis

\begin{tabular}{cccccc}
\hline Rock Stratum & Elasticity Modulus $(\mathrm{GPa})$ & Poisson's ratio & Density $\left(\mathrm{g} / \mathrm{cm}^{3}\right)$ & Friction Angle $\left(^{\circ}\right)$ & Cohesive Force $(\mathrm{Mpa})$ \\
\hline Limestone & 24.50 & 0.27 & 2.70 & 45.28 & 9.85 \\
Anhydrite & 5.00 & 0.28 & 2.70 & 40.00 & 0.08 \\
Rock Bolt & 170.00 & 0.30 & 7.80 & -- & -- \\
Initial liner & 31.00 & 0.17 & 2.50 & 54.90 & 3.18 \\
\hline
\end{tabular}

Table 6: Summary fits of swelling stress-strain changing over time for swelling constitutive model with consideration of time effect

\begin{tabular}{ccccc|ccc}
\hline \multicolumn{5}{c|}{ Parameters } & \multicolumn{3}{c}{ Goodness of fit } \\
$\varepsilon_{\infty}(\%)$ & $\sigma_{\max }(k P a)$ & $a$ & $b$ & $c$ & R-square & RMSE & SSE \\
\hline 52.04 & 1510 & 150.30 & 0.3954 & 0.0125 & 0.9750 & 0.0011 & $9.4820 E-5$ \\
\hline
\end{tabular}

Note:Parameter $\varepsilon_{\infty}(\%)=52.04 \%$ indicates that swelling strain of this type anhydrite is able to reach to $52.04 \%$ after complete free swelling. $\sigma_{\max }=1510 \mathrm{kPa}$ indicates that swelling stress under swelling strain inhibited completely of this type anhydrite is able to reach to $1510 \mathrm{kPa}$. R-square is coefficient of determination. RMSE (root-mean-square error)is a frequently used measure of the differences between values predicted by a model and the values actually observed. SSE(Sum of Squares Due to Error)is used to measure the total deviation of the response values from the fit to the response values. RMSE and SSE values closer to 0 indicate a fit that is more useful for prediction.

Table 7: Summary numerical simulation results using ANSYS

\begin{tabular}{|c|c|c|c|c|c|c|c|c|}
\hline Crown & Convergence & Maximal & Maximal & Maximal & Maximal & Maximal & Maximal & Maximal \\
\hline \multirow{3}{*}{$\begin{array}{l}\text { Settlement } \\
(\mathrm{cm})\end{array}$} & of Wall & Deformation & Axial & Tensile & Axial & Shearing & Bending & Compressive \\
\hline & $(\mathrm{cm})$ & of $\mathrm{SR}$ & Force of & Stress of & Force of & Force of & Moment of & Stress of \\
\hline & & $(\mathrm{cm})$ & $\operatorname{LE}(k N)$ & $\mathrm{RB}(M P a)$ & $\mathrm{BE}(k N)$ & $\mathrm{BE}(N)$ & $\operatorname{BE}(N \cdot m)$ & $\mathrm{FL}(M P a)$ \\
\hline 24.50 & 54.00 & 27.60 & 197.93 & 100.4 & 503.96 & 1.90 & 0.30 & 7.40 \\
\hline
\end{tabular}

Note:SR is surrounding rock. LE is Link1 element. RB is rock bolt. BE is Beam3 element. FL is first lining. 


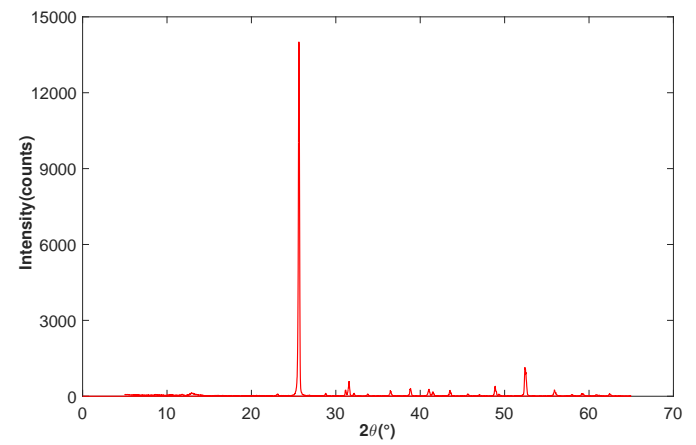

(a)

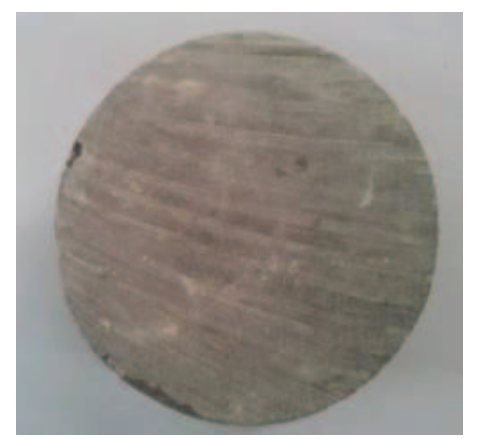

(b)

Fig. 1: (a) is one result of X-ray diffraction analysis. All four anhydrite samples for quantitative analysis show similar peaks as the above (a). There are differences between X-ray diffraction analysis result of anhydrite in this paper and that reported by [19]. (b) is an anhydrite sample after processing which is bluish-grey
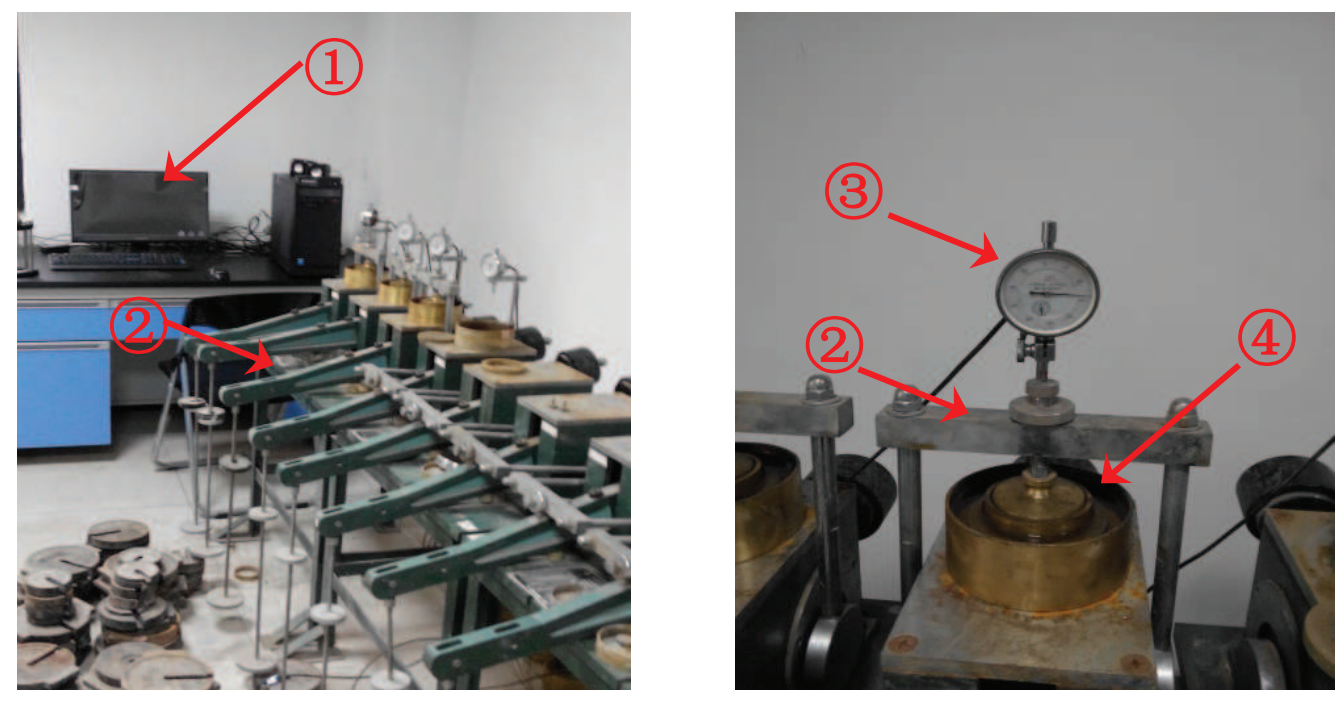

Fig. 2: The left are the oedometer apparatuses linked with the data auto sampling system. The right is one of the test apparatuses. (1) is computer used for indication. (2) is loading frame, it can be moved away when measuring the vertical deformation without loading. (3) is dial gauge linking with the computer. (4) is water container, into which a sample is put. 


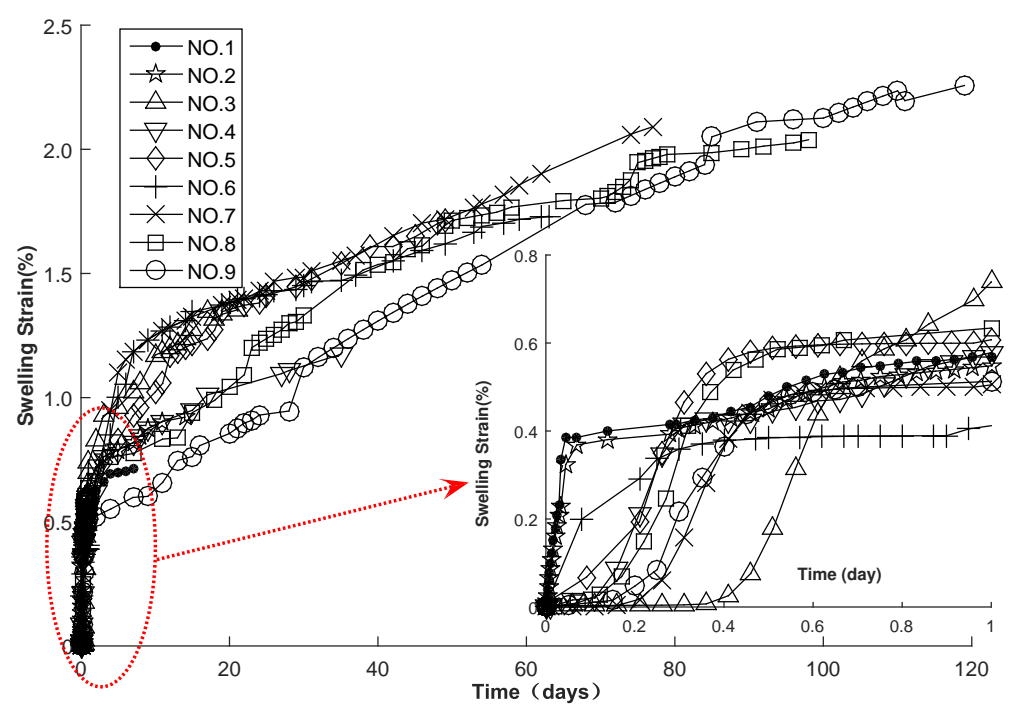

Fig. 3: The relationship between swelling strain and time from free swelling with lateral confinement. Inner figure is the swelling strain-time in the first day.

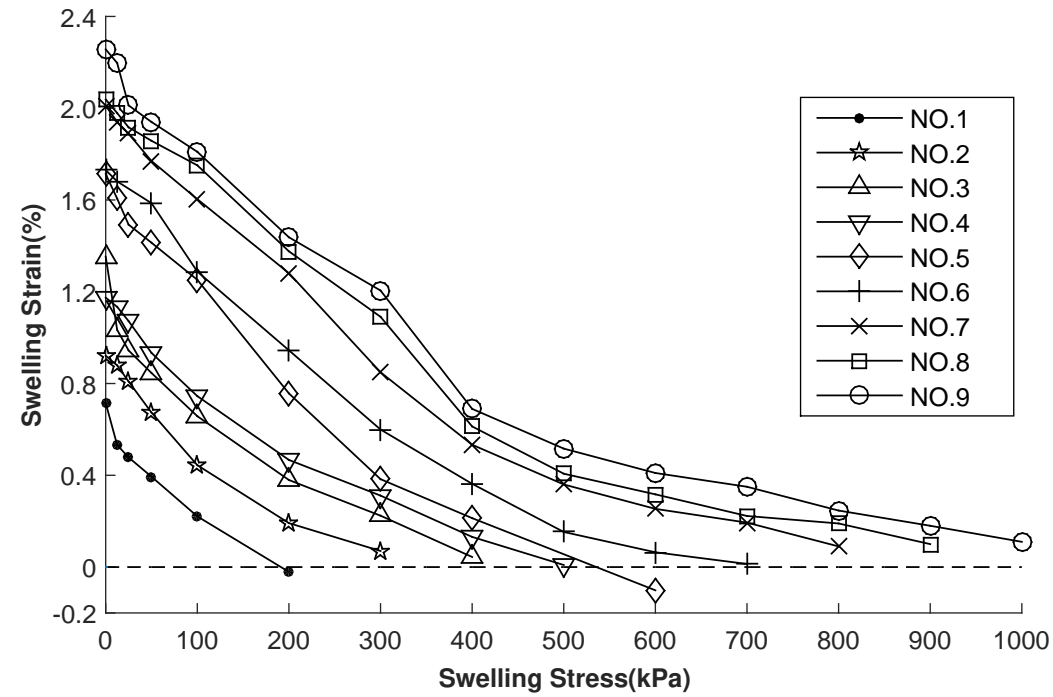

Fig. 4: The relationship between swelling stress and strain from axial swelling stress and strain with lateral confinement. 


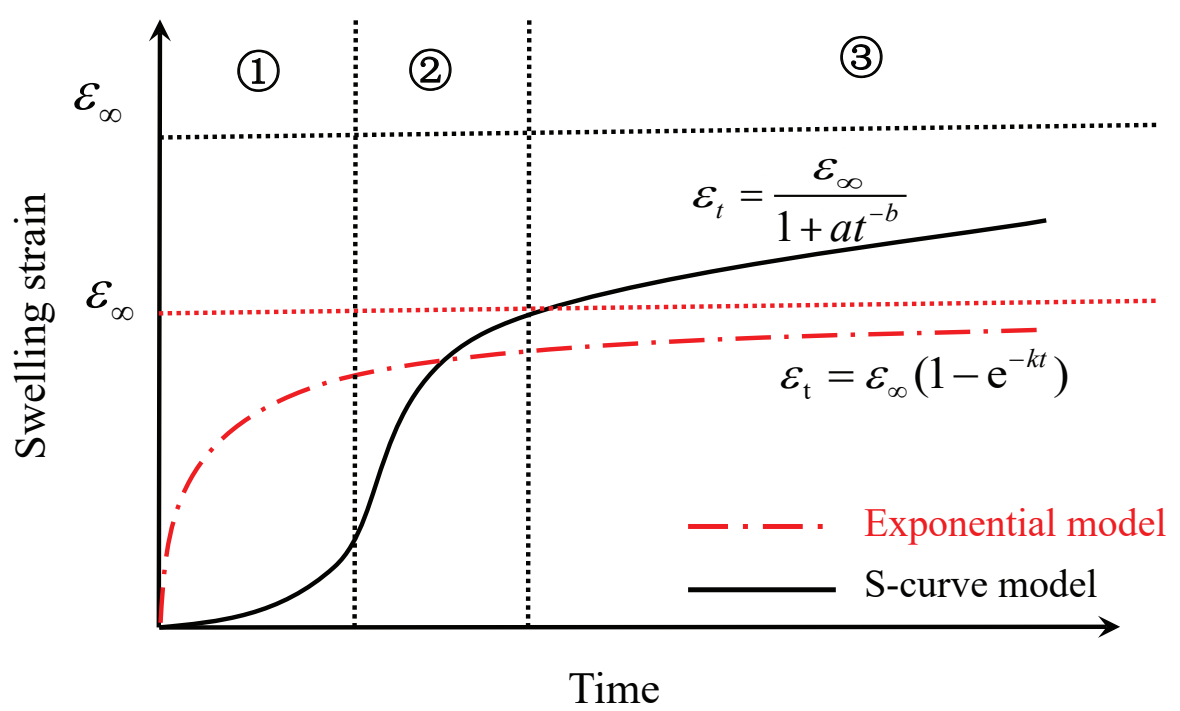

Fig. 5: Introduction of two kinds of swelling strain-time model. The red line is exponential model employed in [23]. The black line is S-curve model employed in this paper. In the representation of S-curve model, there are three clearly defined phase: (1) The growth rate of swelling strain increases over time. This phase can be very short, for example the data of NO.1 and NO.2 samples in Figure.3. (2) Swelling strain increases rapidly, while the growth rate of it decreases over time. (3) The increase of swelling strain is relatively stable, and is able to last a long time and will close to a maximal swelling strain $\varepsilon_{\infty}$. (1) and (2) are unstable phases of growth rate of swelling strain, which is controlled by the combined effect of both osmotic effect and hydration effect. (3) is a relatively stable increase phase of swelling strain, of which dominate is hydration effect. 
(a)

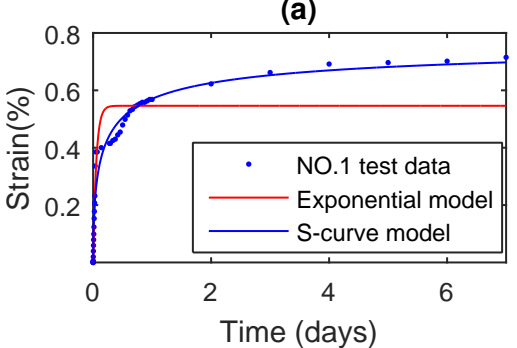

(d)

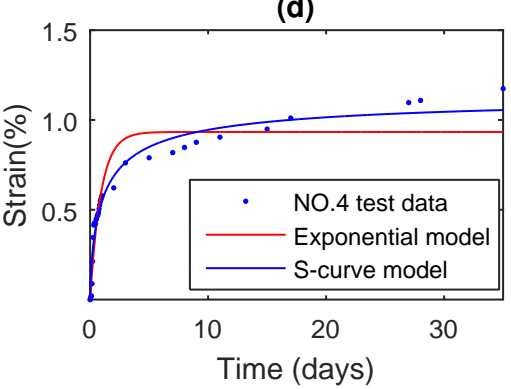

(g)

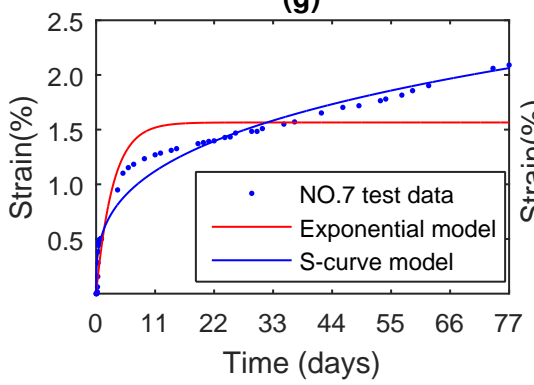

(b)

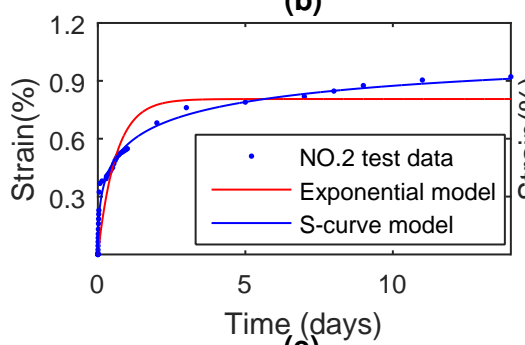

(e)

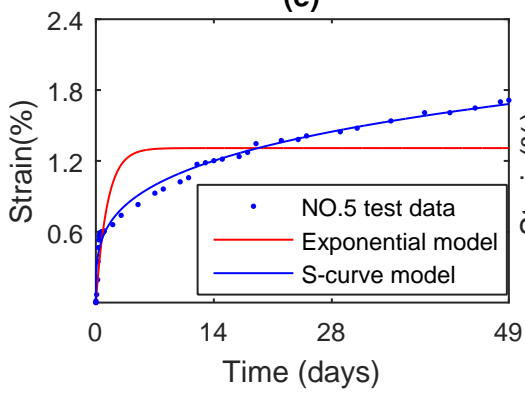

(h)

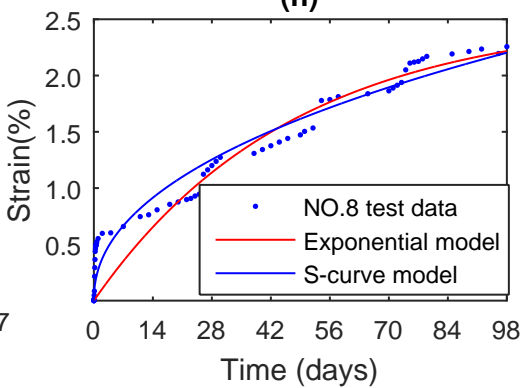

(c)

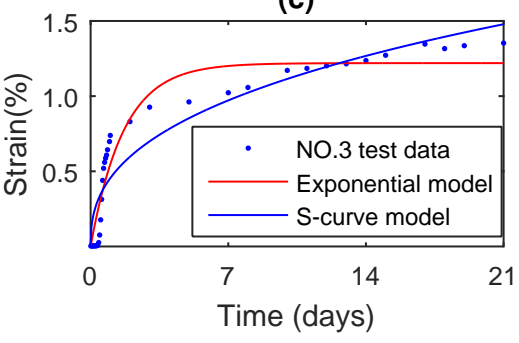

(f)

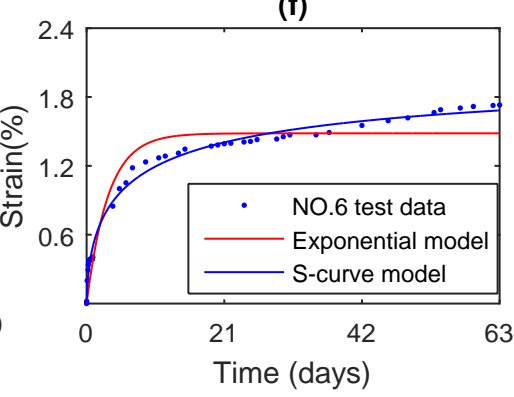

(i)

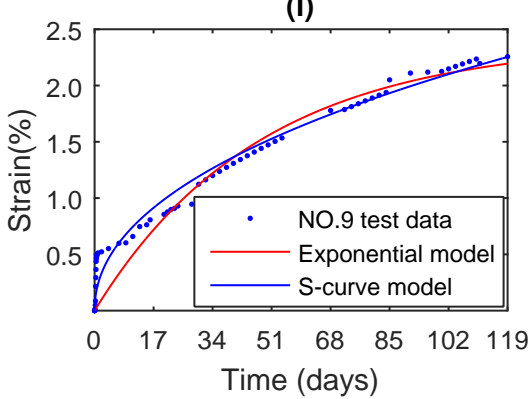

Fig. 6: Swelling strain-time fitting results of nine samples by exponential model and S-curve model, respectively. 


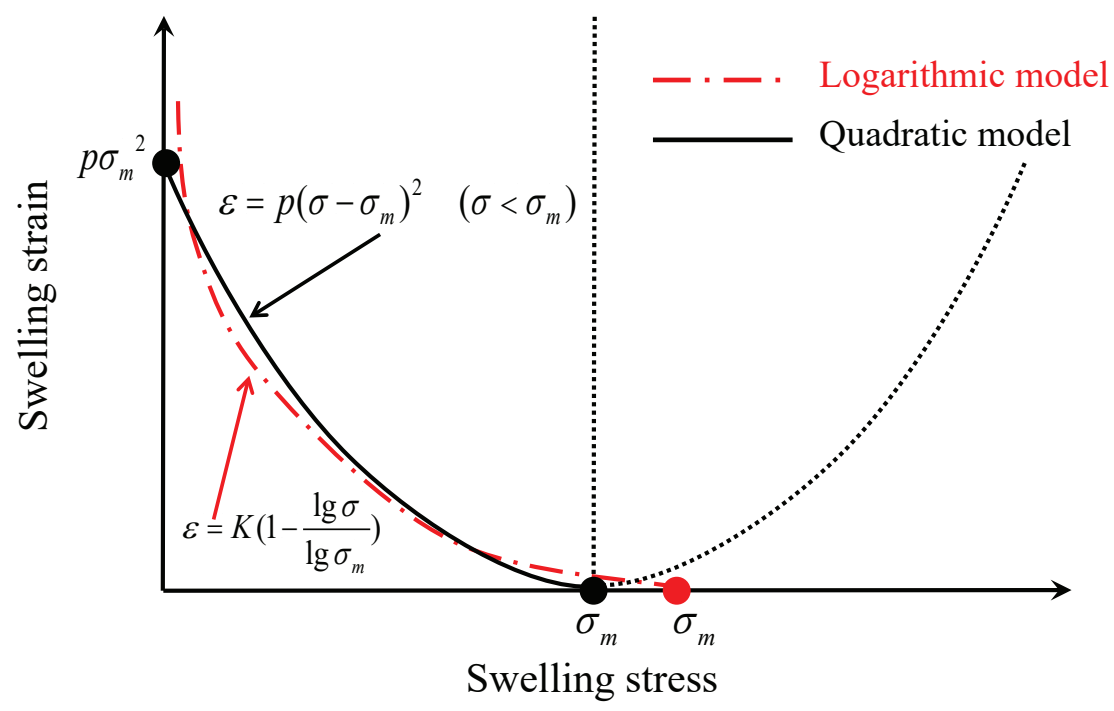

Fig. 7: Introduction of two kinds of swelling stress-strain model. The red line is logarithmic model employed in [28]. The black line is quadratic model employed in this paper. The intersection of models with X-axis, i.e. $\sigma_{m}$, represents the swelling stress under swelling strain inhibited completely. If swelling stress trends to zero, the swelling strain of logarithmic will trend to infinity, while that of quadratic model will have a intersection with Y-axis, i.e. a constant value $p \sigma_{m}^{2}$. 
(a)

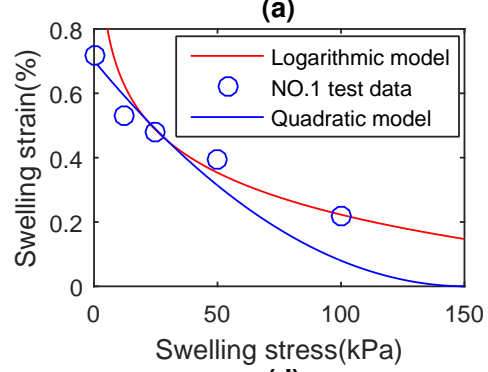

(d)

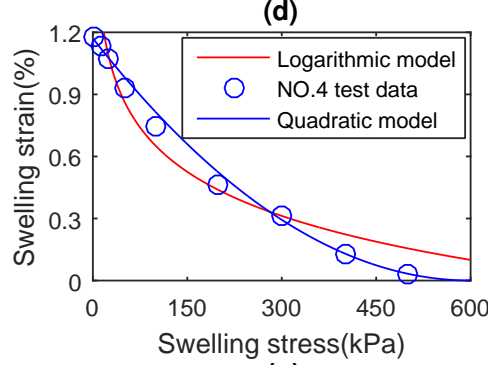

(g)

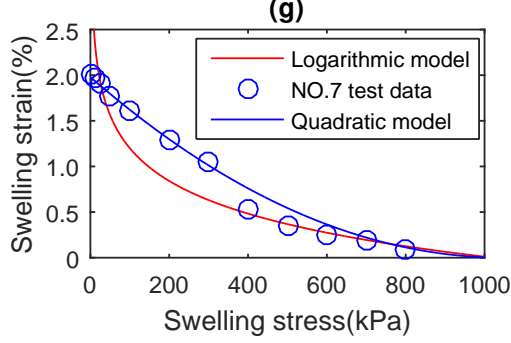

(b)

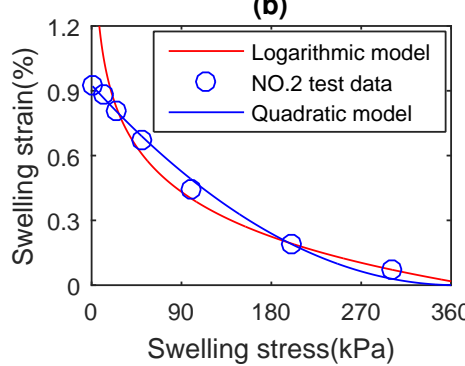

(e)

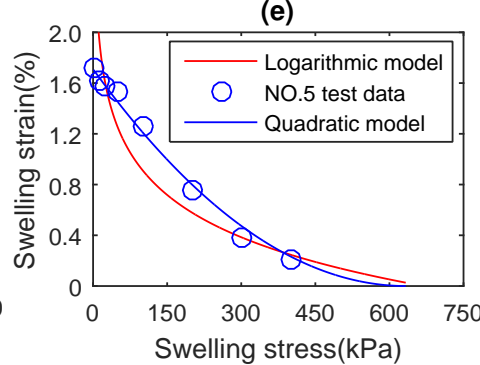

(h)

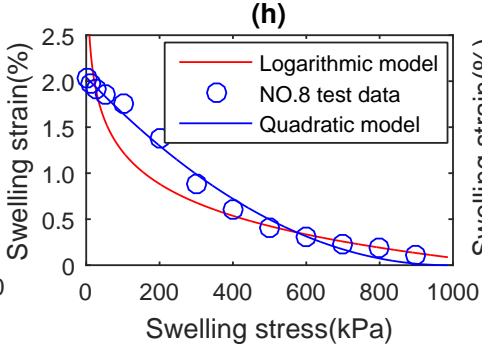

(c)

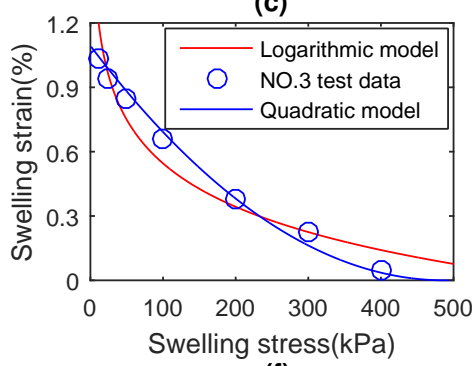

(f)

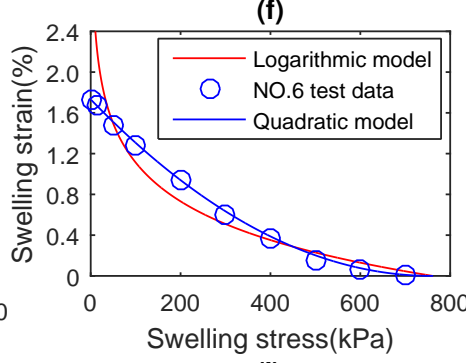

(i)

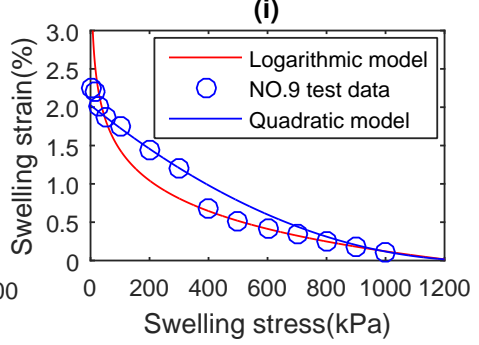

Fig. 8: Swelling stress-strain fitting results of nine samples by logarithmic model and quadratic model, respectively.

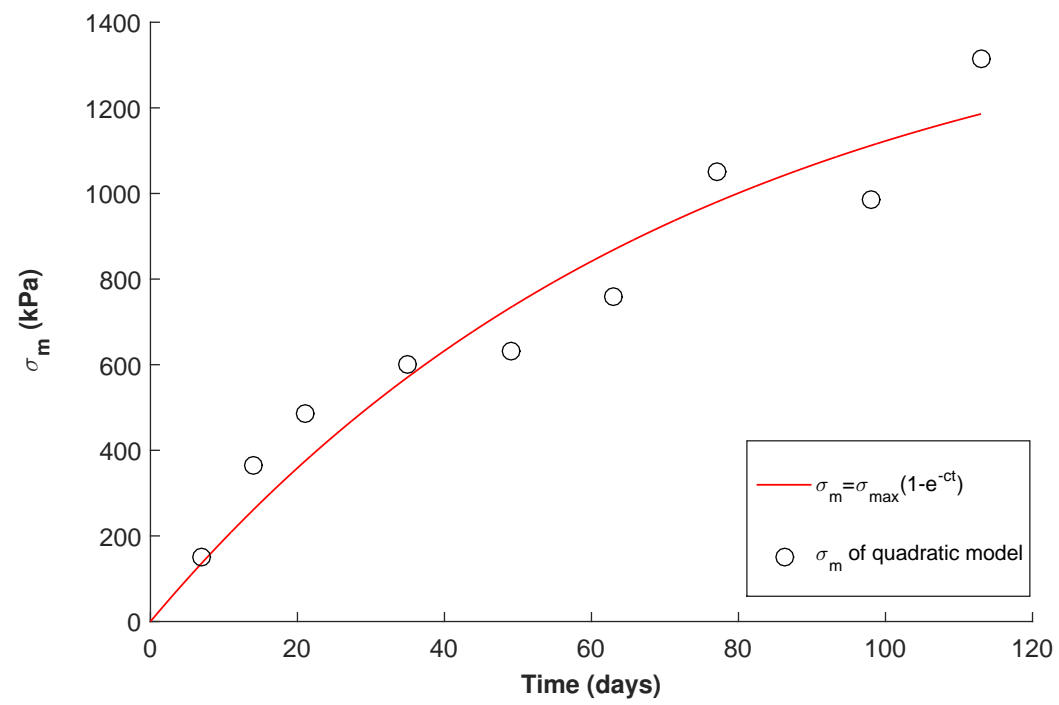

Fig. 9: The relationship between $\sigma_{m}$ of quadratic model and time. $\sigma_{m}$ comes from Table 4 . In the fitting results, coefficient $\sigma_{\max }$ is $1515 \mathrm{kPa}$, coefficient $c$ is 0.01351 , and R-square is 0.9202 


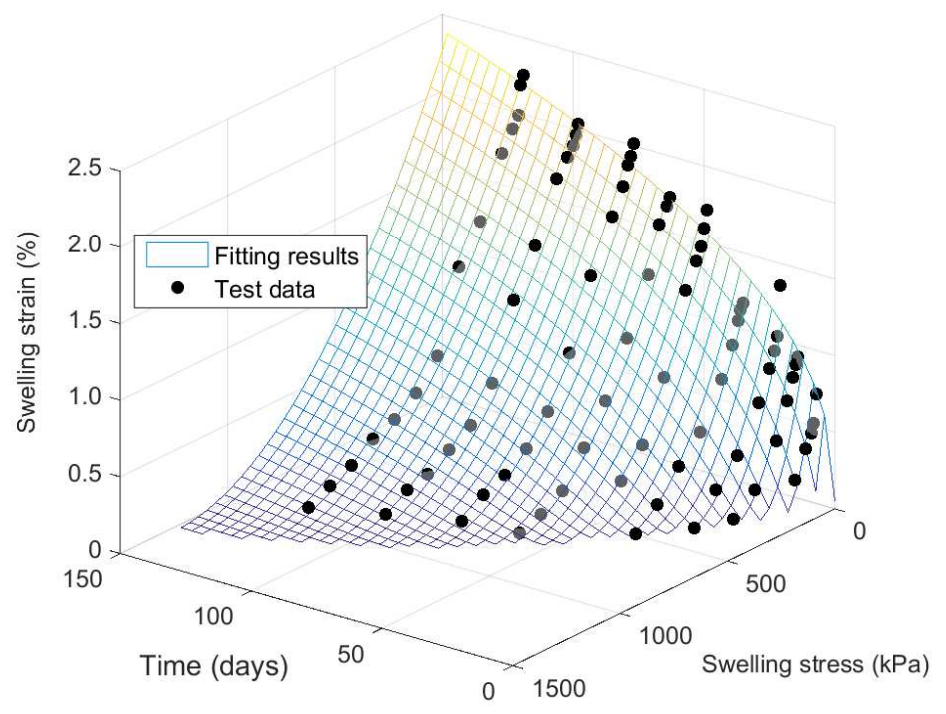

Fig. 10: Comparisons between test data and prediction of swelling constitute model with consideration of time effect.

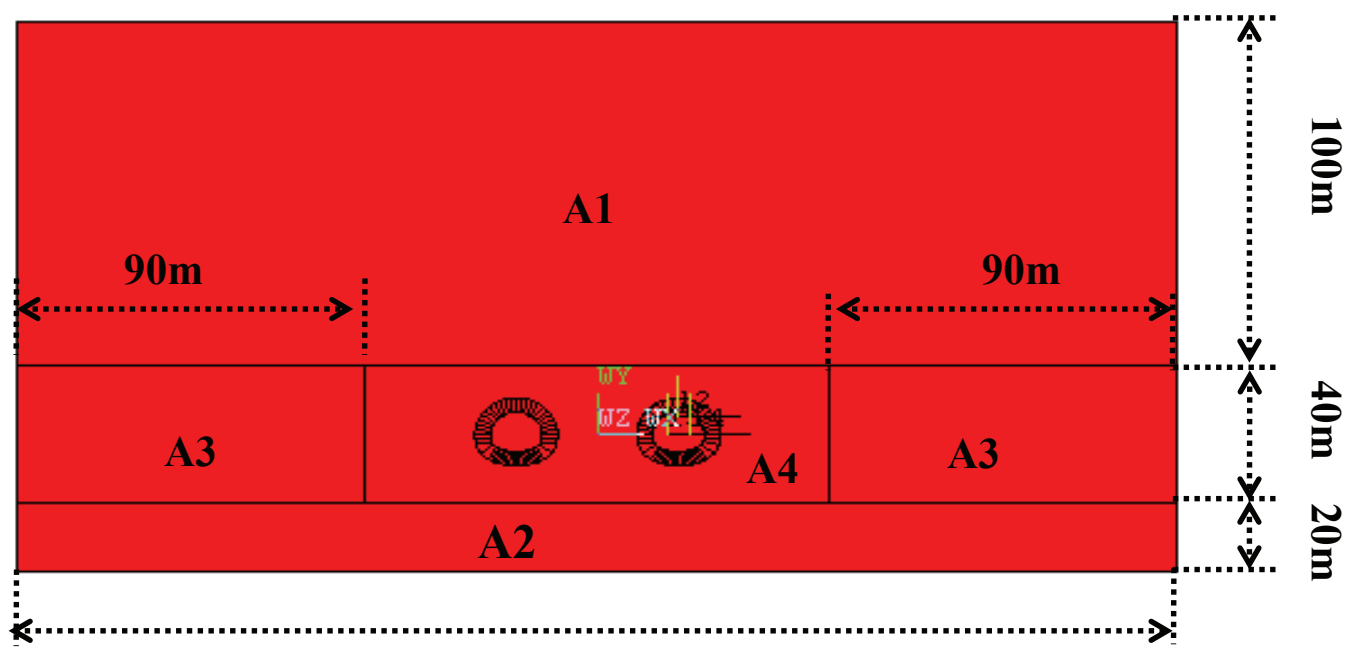

$300 \mathrm{~m}$

Fig. 11: 2D finite model. $A 1$ and $A 2$ are limestone stratums which are unable to swell. $A 3$ and $A 4$ are anhydrite stratums. $A 4$ is subjected to underground water, so it is able to swell, while $A 3$ is far away from the tunnel and free of underground water, so $A 3$ does not need to consider swelling. 


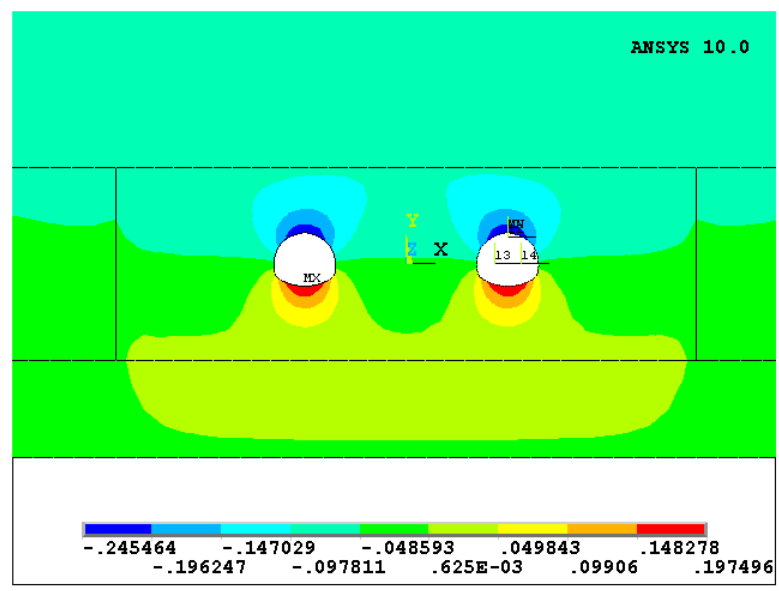

(a) Y direction displacement on day 36 (Unit: $\mathrm{m}$ )

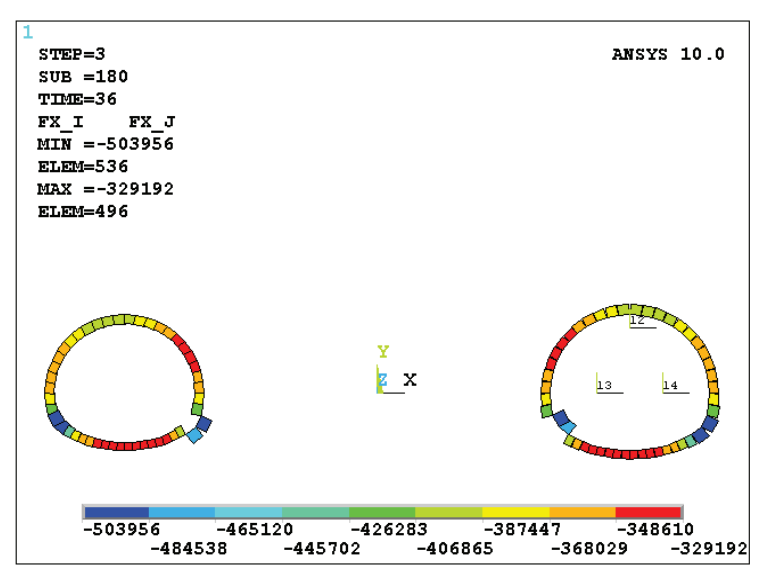

(c) Axial force of first lining on day 36 (Unit: N)

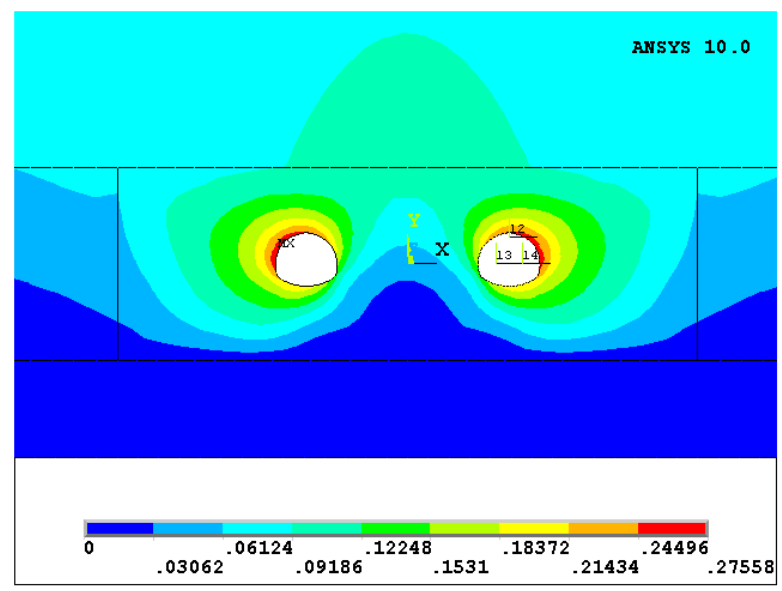

(b) Resultant displacement on day 36 (Unit: m)

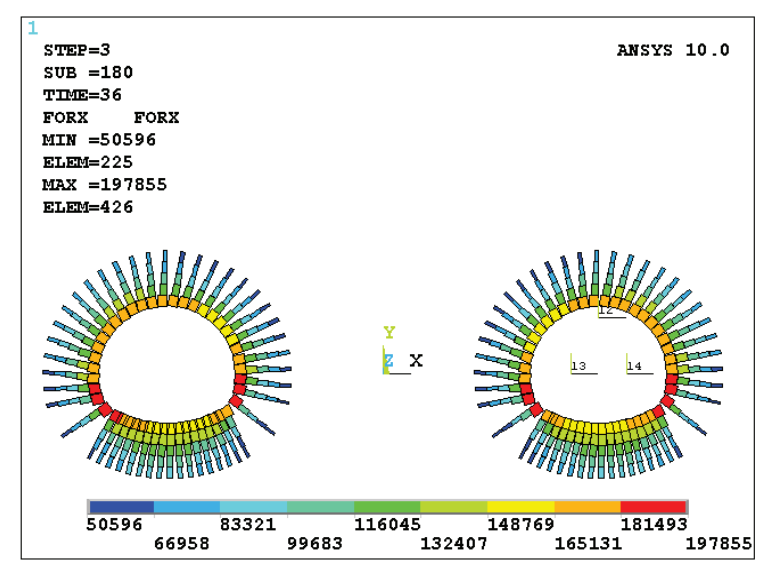

(d) Axial force of rock bolt on day 36 (Unit: N)

Fig. 12: The results of numerical simulation 